\title{
Academic performance of
} undergraduate dental students with learning disabilities

\author{
Urzinger, Sebastian
}

http://hdl.handle.net/10026.1/8510

\subsection{8/sj.bdj.2017.125}

British Dental Journal

Springer Science and Business Media LLC

All content in PEARL is protected by copyright law. Author manuscripts are made available in accordance with publisher policies. Please cite only the published version using the details provided on the item record or document. In the absence of an open licence (e.g. Creative Commons), permissions for further reuse of content should be sought from the publisher or author. 
"This is a final author's draft of the paper submitted for publication in the British

Dental Journal 2017". DOI: 10.1038/sj.bdj.2017.125

Title:

Academic Performance of Undergraduate Dental Students with Learning Disabilities.

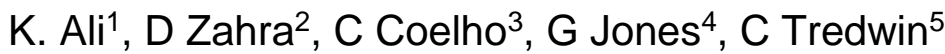

${ }^{1}$ Associate Professor / Consultant in Oral Surgery, Peninsula Dental School,

Plymouth University

2 Senior Psychometrician Plymouth University Peninsula Schools of Medicine and Dentistry

${ }^{3}$ Senior Lecturer, Peninsula Dental School, Plymouth University

${ }^{4}$ Director of Undergraduate Dental Studies

${ }^{5}$ Head of Peninsula Dental School, Plymouth University

Corresponding Author:

Dr. Kamran Ali (First / Correspondence Author)

PhD, MMEd, BDS (Hons), FDS RCS (Eng.), FCPS (Pak), FFD RCSI (Ire), SFHEA

Associate Professor / Consultant in Oral Surgery,

Peninsula Dental School

Room C402 Portland Square

Drake Circus, University of Plymouth

Plymouth, Devon PL4 8AA

United Kingdom

Email: kamran.ali@plymouth.ac.uk

Tel: (+44) (0) 1752586768

Fax:(+44) (0) 1752586788

Abstract: 
Aims: To compare the academic performance of undergraduate dental students with known learning disabilities (LDs) to their peers.

Methods: This study analysed the results of students in applied dental knowledge (ADK) progress tests across four cohorts of dental students. A mixed model analysis of variance (ANOVA) was conducted to compare the performance of students with known LDs to their peers. ADK test sitting was treated as a repeated measures variable, and the outcome variable of interest was percentage score on the ADK.

Results: Students' performance data on five ADK test sittings (ADK15, ADK16, ADK17, ADK18, and ADK19) by Disability showed a significant main effect of Test but no significant effect of Disability or any interaction between Disability and Test.

Conclusions: This is the first study which explores the academic performance of dental students with a diagnosis of disability. The findings give reassurance to all stakeholders that, within the study population, students with LDs are not disadvantaged in knowledge-based assessments, demonstrating compliance with the legal obligations. Further research is required to explore how generalisable these findings are, as well as assess academic, clinical, and behavioural attributes of students with learning disabilities. 


\section{Introduction}

Learning disabilities (LDs) is a generic term used in Higher Education settings to refer to a heterogeneous group of disorders manifesting as significant difficulties in the acquisition and use of listening, speaking, reading, writing, reasoning, or mathematical abilities, or of social skills. ${ }^{1,2}$ LDs are commonly classified into Specific and Non-specific groups. Specific LDs include conditions such as Dyslexia, Dyscalculia, Development Coordination Disorder (DCD), Attention Deficit Disorder (ADD) and Attention Deficit Hyperactivity Disorder (ADHD). ${ }^{3,4}$ Non-specific LDs are caused by deficits in auditory processing, visual processing, speed of processing, or any combination of these. LDs are the largest group of disabilities in higher education institutes (HEls), including medical schools and usually reflect a discrepancy between an individual's academic achievement and their apparent capacity to learn. ${ }^{2,5}$

It is estimated that approximately $6 \%$ of students enrolled at all higher educational levels in England during 2012-13 had specific LDs, representing an increase by over one third since 2008-9. ${ }^{6}$ With widening access to university education in the United Kingdom, the numbers are likely to rise further. ${ }^{7}$ Crucially, a large proportion of students in higher education are not aware of their LDs and these are typically investigated when students who were previously successful in their studies tend to struggle in medical schools. ${ }^{8}$

It is recognised that individuals with formally assessed disabilities are underrepresented in $\mathrm{HE}$ in the UK. ${ }^{9}$ Given the national objectives to expand the HE sector and promote an inclusive culture, disability should not be considered a barrier as this approach may obscure talent that may be mutually beneficial to both HE and the 
individuals. ${ }^{10}$ In this regard legislation in the UK is based on The Disability Discrimination Act, 1995, The Disability Act, 2001 and the Equality Act, 2010. ${ }^{11}$ It protects disabled students from being treated "less favourably". Once there has been a disability assessment and provision of a Disabled Student Allowance (DSA), it is mandatory for HEls to make specific "reasonable adjustments" to provision for students with disability to ensure that they are not disadvantaged. ${ }^{10}$ What is a reasonable adjustment is dependent on an individual's needs but these have included specialist tuition support, assistive technology and assessment arrangements, such as extra time, readers, scribes, solo rooms and papers printed on different coloured paper.

Diagnosis of LDs still carries a stigma that may result in non-disclosure of conditions such as dyslexia. ${ }^{12}$ Consequently, a large proportion of students with LDs may potentially remain undiagnosed at the start of an educational programme and may even graduate without a diagnosis. ${ }^{5}$ Moreover, despite the significant prevalence of LDs, many educators in HE including professional courses may not have adequate awareness of LDs. ${ }^{8}$ Under-diagnoses of LDs may have an adverse impact on students' academic and clinical performance and ultimately their well-being. ${ }^{12}$ Therefore, educational institutions need to ensure a supportive environment where students with disabilities feel welcome and protected.

There is very limited published literature available on performance of dental students with disabilities and this study was undertaken to compare the academic performance of students with known LDs to their peers. Peninsula dental school follows an enquiry-based curriculum for the Bachelor of Dental Surgery (BDS) course and is based in primary care settings. ${ }^{13,14}$ Until 2012 admission to the fouryear BDS programme was restricted to graduates. Subsequently, the BDS 
programme was extended to five years and allows entry to direct school leavers with $10 \%$ of places reserved for graduate students. The last cohort of students enrolled on the four-year programme graduated in 2016.

Dental progress testing aimed at assessing applied dental knowledge (ADK) constitutes the principal form of summative academic assessment at Peninsula dental school. ${ }^{15}$ Progress testing is a form of longitudinal feedback-oriented assessment which is now well-established in medical schools worldwide including the UK. ${ }^{16-18}$ The standard of ADK test is set at the level of knowledge expected from a newly qualified graduate and mapped against the learning outcomes of dentists specified by the General Dental Council. ${ }^{19}$ Students from year two and beyond sit the same ADK tests which are conducted on multiple occasions during each academic year. The tests are formative in year two and summative thereafter. Students' scores on ADK tests are used to measure growth in knowledge within and across each academic year until graduation. ${ }^{20}$ The students carry their end-of-year ADK grade to the next academic year to ensure continuity of assessment. Evidence from the literature shows that the use of progress testing facilitates longitudinal mapping of students' academic performance and allows more reliable and valid decision making regarding their progression. ${ }^{21}$

This aim of this study was to investigate any differences in academic performance of undergraduate dental students with a known disability to their peers in dental progress tests. 


\section{Methods}

Study Design: It was an exploratory study to compare the academic performance of students with a known learning disability with their peers. Examination data related to five progress test sittings conducted over a period of two years for undergraduate dental students was collated. Tests numbered ADK15 and 16 were conducted in the 2014-15 academic year, while Tests 17, 18, and 19 were conducted in 2015-16 academic year.

Each progress test was based on 100 single best answer multiple choice items. The students selected their answer from one of five options or could choose a 'Don't Know' (DK) option. A score 1 mark was awarded for each correct answer; minus 0.25 for an incorrect answer and zero for 'Don't Know'. All tests were conducted on paper. Several adjustments were made for students with LDs including: provision of a separate room for each student; non-medical support staff who also functioned as note-takers and readers; questions printed on a cream colour paper; and allowing extra 20 minutes with additional rest breaks of up to 20 minutes to complete each test.

Setting: Peninsula Dental School, Plymouth, United Kingdom

Participants: The study population consisted of four cohorts of undergraduate dental students. The 2011-12 and 2012-13 cohorts were enrolled on a four-year BDS programme and sat two progress tests in each academic year. The 2011-12 cohort graduated after ADK16, so there is only data available for their performance in ADK15 and ADK16. The 2012-13 cohort sat ADK15, 16, 17, and 19. The students in 2013-2014 and 2014-2015 cohorts were enrolled on a five-year programme and sat 
three tests in 2015-16 due to a change in frequency of progress tests from two to three in 2015-16.

\section{Data Analysis}

With regards to disability, the students were categorised as follows:

- No known disability

- A specific learning disability

- Non-specific learning disabilities

ADK was treated as a repeated measures variable, and the outcome variable of interest was percentage score on the ADK. All statistics were computed using SPSS (IBM Corp. Released 2013. IBM SPSS Statistics for Windows, Version 22.0 Armonk, NY: IBM Corp.) R was used to depict differences in percentage ADK scores. ${ }^{22}$ 


\section{Results}

The sample size of students consisted of 250 students with 137 females and 113 males. The distribution of sample across four cohorts is depicted in Table 1. Homogeneity assumptions were met in all cases (Mauchly's and Levene's tests as appropriate).

Table 1 Distribution of students with and without disability

\begin{tabular}{|l|l|c|c|c|c|c|}
\hline \multirow{2}{*}{ Cohort } & \multirow{2}{*}{ Disability Status } & \multicolumn{5}{|c|}{ Sample Sizes (N) } \\
\cline { 3 - 7 } & & ADK15 & ADK16 & ADK17 & ADK18 & ADK19 \\
\hline 1112 & No Known Disability & 66 & 66 & -- & -- & -- \\
\cline { 2 - 7 } & Specific LD & 4 & 4 & -- & -- & -- \\
\hline \multirow{3}{*}{1213} & Non- Specific LD & 2 & 2 & -- & -- & -- \\
\hline & No Known Disability & 53 & 54 & 56 & -- & 56 \\
\cline { 2 - 7 } & Specific LD & 3 & 3 & 3 & -- & 3 \\
\hline \multirow{3}{*}{1314} & Non- Specific LD & 3 & 3 & 3 & -- & 3 \\
\hline \multirow{3}{*}{1415} & No Known Disability & 56 & 57 & 57 & 57 & 57 \\
\cline { 2 - 7 } & Specific LD & 5 & 5 & 5 & 5 & 5 \\
\hline & Non- Specific LD & -- & -- & -- & -- & -- \\
\cline { 2 - 7 } & No Known Disability & -- & -- & 48 & 48 & 48 \\
\cline { 2 - 7 } & Specific LD & -- & -- & 5 & 5 & 5 \\
\hline & Non- Specific LD & -- & -- & 1 & 1 & 1 \\
\hline
\end{tabular}

With regards to the academic background of the participants, all students in the 1112 and 1213 cohorts were graduates. The students in the 1314 cohort consisted of 53 direct school leavers and 8 graduates; the latter included 2 graduates with specific LDs. The 1415 cohort included 45 direct school leavers and10 graduates. However, there were no graduates with any type of LDs in this cohort.

Due to the structure of the programme and its assessments (detailed in the methods) there were some ADK tests which were not sat by some cohorts. To overcome this, the results were analyses in four separate ANOVAs (one for each cohort), thus 
factoring out Cohort as a source of variability. Comparisons across tests and stages within each cohort was then conducted and the differences in growth in knowledge between students with and without disability are illustrated in Figure 1.

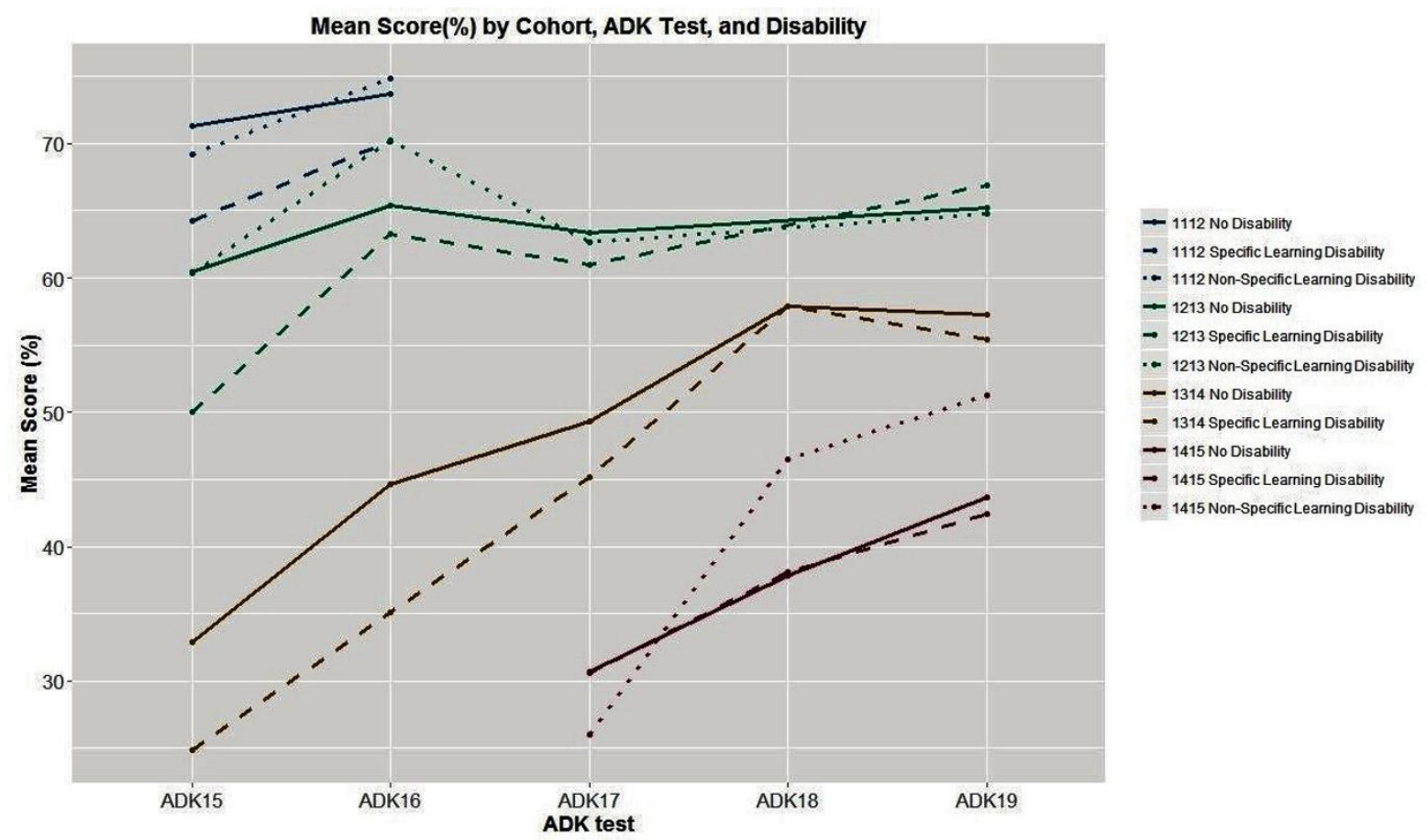

Figure 1 Mean scores by cohort, ADK test, and Disability

A 2 Test (ADK15, ADK16) by Disability (No-Known Disability, Specific LD, NonSpecific LD) repeated measures ANOVA for the 1112 Cohort reveals a significant main effect of Test, such that ADK16 scores are higher than ADK15 scores $\left[F(1,69)=4.934, \quad p=.030, \quad \eta^{2} p=.067\right], \quad$ but no significant effect of Disability $\left[F(2,69)=.880, p=.419, \eta^{2} \mathrm{p}=.025\right]$, or any interaction between Disability and Test $\left[F(2,69)=.615, p=.544, \eta^{2} p=.018\right]$. 
A 4 Test (ADK15, ADK16, ADK17, ADK19) by Disability (No-Known Disability, Specific LD, Non-Specific LD) repeated measures ANOVA for the 1213 Cohort reveals a significant main effect of Test $\left[F(3,168)=7.522, p<.001, \eta^{2} p=.118\right]$, but no significant effect of Disability $\left[F(2,56)=.258, p=.773, \eta^{2} p=.009\right]$, or any interaction between Disability and Test $\left[F(6,168)=1.471, p=.191, \eta^{2} p=.050\right]$. The main effect of Test reveals that scores for ADK16>ADK15 $(p<0.001)$ and ADK19>ADK15 $(p=.004)$.

A 5 Test (ADK15, ADK16, ADK17, ADK18, ADK19) by Disability (No-Known Disability, Specific LD, Non-Specific LD) repeated measures ANOVA for the 1314 Cohort reveals a significant main effect of Test $\left[F(4,236)=69.758, p<.001, \eta^{2} p=.542\right]$, but no significant effect of Disability $\left[F(1,59)=1.594, p=.212, \eta^{2} p=.026\right]$, or any interaction between Disability and Test $\left[F(4,236)=1.980, p=.098, \eta^{2} p=.032\right]$. The main effect of Test reveals that all test scores differ significantly $(p<.001)$ except the scores for ADK18 and ADK19 ( $p=.991)$.

A 3 Test (ADK17, ADK18, ADK19) by Disability (No-Known Disability, Specific LD, Non-Specific LD) repeated measures ANOVA for the 1415 Cohort reveals a significant main effect of Test $\left[F(1,102)=15.129, p<.001, \eta^{2} \mathrm{p}=.229\right]$, but no significant effect of Disability $\left[F(2,51)=.494, p=.613, \eta^{2} p=.019\right]$, or any interaction between Disability and Test $\left[F(4,102)=.160, p=.958, \eta^{2} p=.006\right]$. The main effect of Test reveals that scores for ADK18>ADK17 $(p=.002)$ and ADK19>ADK17 $(p<.001)$, but ADK19 ADK18 $(p=.123)$. 


\section{Discussion}

This is a pioneering study comparing the academic performance of students with disability with their peers in an undergraduate dental programme. The results of this exploratory study show that the academic performance of students with disability was at par with their peers and any differences were non-significant. No comparable published studies were identified from the dental education literature. Nevertheless, the findings of this study corroborate with the results of studies on medical students in the UK. A longitudinal study on medical students reported that students with disability perform poorly in written assessments such as extended matching questions (EMQ), short answer question (SAQ) compared to their peers. ${ }^{23}$ However, these differences are mainly observed in earlier years of the programme and may be partly due to delayed adjustment to medical school or implementation of assessment concessions such as allowing extra time. Another study on medical students in years 1 and 2 did not report any effect of LDs on examination results based on the scores of written assessments (EMQs, MCQs, SAQs) and Objective structured clinical examinations. $^{24}$ However, students with LDs may find clinical environments particularly challenging which may affect their performance. ${ }^{7,8}$ In any case, academic and clinical tutors require a greater awareness and preparedness to meet the needs of students with LDsand design their learning resources to be more inclusive from the outset. ${ }^{25}$

Although the students with disability were a small group in each cohort, our approach to data analyses allowed clear identification of the effects of each factor and provides an easily interpretable, exploratory, analysis of these effects. The assumptions of the analysis were met by the data (normality, skew, kurtosis, homogeneity of variance and residuals), though it is acknowledged that deviations from these assumptions 
may be more difficult to detect with small sample sizes. ANOVAs are generally considered more robust to differences in sample size than possible alternative analyses. ${ }^{26}$ Though this robustness is reduced in factorial designs, the proportions of students with and without a disability was similar across cohorts and tests, so the variation in sample size was not confounded with other factors.

Over the years the government funding for disabled students in HE provided a range of support, including the purchase of specialist equipment and provision of support workers. There is now a shift away from DSA-funded support to HEl-funded support. From September 2016, this funding will be the responsibility of universities who will need to provide for non-medical support staff, including note-takers, and readers and examination support workers. Various stakeholders' representative bodies including the National Students Union have expressed concerns at these changes as they may have an adverse impact on students with disability including an increase in graduate loan repayments. ${ }^{27}$ Therefore, the universities now have an increased level of responsibility and the dental schools also need to work with their parent universities to ensure that an appropriate level of support is provided to students with disability.

With regards to the limitations of this study, the data reported is from a single undergraduate dental programme and it would be helpful to explore the performance of disabled students at other dental schools in the UK and beyond. This will be particularly useful in overcoming sample-size issues, allowing robust factorial and alternative analyses to further investigate any potential difference in performance. Such collaborative efforts may also enable distinctions to be drawn between different types of reported disability which may require different adjustments. Given that declaration of disability is voluntary, it is possible that some students classified as 
"No disability" in this study may not have declared any disability and / or may not have been assessed formally. Nevertheless, students with borderline/unsatisfactory academic performance are offered study skills support and are also signposted to the disability assessment services at the university.

Academic performance represents only one of the several attributes expected from dental students. Given the challenges of clinical dentistry involving irreversible procedures on patients and communicating effectively with colleagues and patients, it would be worthwhile to compare the skills of students with disabilities to those of their peers. Such studies in the future would be valuable not only to inform the educational policies of the government in HE but they would also provide immense opportunities for the dental schools to reflect on the provisions of their support systems and training requirements for the faculty. 


\section{Conclusions}

This is the first study to address a topic which has not been investigated in dental education research and explores the academic performance of dental students with a diagnosis of LDs. The findings give reassurance to all stakeholders that students with LDs are not disadvantaged in knowledge-based assessments and that Peninsula dental school is meeting its legal obligations. The data shows that students with a learning disability, when assessed using the same tests of applied dental knowledge as their peers with no disability, perform at a similar level. However, these findings may be limited to the study population only. Further research is required to explore how generalisable these findings are, as well as assess academic, clinical and behavioural attributes of students with LDs.

\section{Disclosure}

None of the authors have any conflict of interest.

\section{Acknowledgements}

The authors would like to thank Kay Allen, Examinations Officer and Debbie Couch Senior Coordinator (Enrolments \& Student Finance), Plymouth University, Peninsula Schools of Medicine and Dentistry for their help. 


\section{References}

1. Kavale KA, Forness SR. What definitions of learning disability say and don't say: a critical analysis. J Learn Disabil. 2000 May-Jun;33(3):239-56. Review.

2. Lyon GR. Learning disabilities. Future Child. 1996 Spring;6(1):54-76. Review.

3. Pino M, Mortari L. The inclusion of students with dyslexia in higher education: a systematic review using narrative synthesis. Dyslexia. 2014 Nov;20(4):34669.

4. British Dyslexia Association. What are specific learning difficulties? Available at http://www.bdadyslexia.org.uk/educator/what-are-specific-learningdifficulties (Accessed 02 December 2016).

5. Majumder MA, Rahman S, D'Souza UJ, Elbeheri G, Abdulrahman KB, Huq MM. Supporting medical students with learning disabilities in Asian medical schools. Adv Med Educ Pract. 2010 Oct 7; 1:31-9.

6. Higher Education Funding Council for England (HEFCE). Support for Higher Education Students with Specific Learning Difficulties Available at http://www.hefce.ac.uk/media/HEFCE,2014/Content/Pubs/Independentresear ch/2015/SupportforStudentswithSpLD/HEFCE2015_spld.pdf (Accessed December 2016).

7. Morris D, Turnbull P. Clinical experiences of students with dyslexia. J Adv Nurs. 2006 Apr;54(2):238-47.

8. Rosebraugh CJ. Learning disabilities and medical schools. Med Educ. 2000 Dec;34(12):994-1000.

9. Pumfrey PD. Moving towards inclusion? The first-degree results of students with and without disabilities in higher education in the UK: 1998-2005. European Journal of Special Needs Education. 2008 Feb 1;23(1):31-46. 
10. Riddell S, Weedon E, Fuller M, Healey M, Hurst A, Kelly K, Piggott L. Managerialism and equalities: tensions within widening access policy and practice for disabled students in UK universities. Higher Education. 2007 Oct $1 ; 54(4): 615-28$.

11. Department for Education and Skills (DfES). 2003b. Widening participation in higher education. London: DfES.

12. Shrewsbury D. Trainee doctors with learning difficulties: recognizing need and providing support. Br J Hosp Med (Lond). 2012 Jun;73(6):345-9.

13. McHarg J, Kay EJ. Designing a dental curriculum for the twenty first century. Br Dent J 2009: 207: 493-497.

14. McHarg J, Kay EJ. The anatomy of a new dental curriculum. Br Dent J 2008: 204: 635-638.

15. Ali K, Coombes L, Kay E, Tredwin C, Jones G, Ricketts C, Bennett J. Progress testing in undergraduate dental education: the Peninsula experience and future opportunities. Eur J Dent Educ. 2016 Aug;20(3):129-34.

16. Van der Vleuten CPM, Verwijnen GM, Wijnen WHFW. Fifteen years of experience with progress testing in a problem-based learning curriculum. Med Teach. 1996; 18:103-10.

17. Blake JM, Norman GR, Keane DR, Barber Mueller C, Cunnington J, Didyk N. Introducing progress testing in McMaster University's problem-based medical curriculum: psychometric properties and effect on learning. Acad Med. 1996; 71:1002-7.

18. Freeman A, Ricketts C. Choosing and designing knowledge assessments: experience at a new medical school. Med Teach. 2010; 32:578-81. 
19.General Dental Council. "Preparing for practice-dental team learning outcomes for registration." London: General Dental Council 2011.

20. Bennett J, Freeman A, Coombes L, Kay L, Ricketts C. Adaptation of medical progress testing to a dental setting. Med Teach. 2010; 32(6):500-2.

21. Schuwirth L, Bosman G, Henning R, Rinkel R, Wenink A. Collaboration on progress testing in medical schools in the Netherlands. Med Teach. 2010; $32: 476-9$.

22. R Development Core Team (2008). R: A language and environment for statistical computing. R Foundation for Statistical Computing, Vienna, Austria. ISBN 3-900051-07-0. Available at: http://www.r-project.org (Accessed July 2016).

23. Gibson S, Leinster S. How do students with dyslexia perform in extended matching questions, short answer questions and observed structured clinical examinations? Adv Health Sci Educ Theory Pract. 2011 Aug;16(3):395-404.

24. McKendree J, Snowling MJ. Examination results of medical students with dyslexia. Med Educ. 2011 Feb;45(2):176-82.

25. MacDougall M. Dyscalculia, dyslexia, and medical students' needs for learning and using statistics. Med Educ Online. 2009 Feb 7; 14:2.

26. Keselman HJ, Huberty CJ, Lix LM, Olejnik S, Cribbie RA, Donahue B, Kowalchuk RK, Lowman LL, Petoskey MD, Keselman JC, Levin JR. Statistical practices of educational researchers: An analysis of their ANOVA, MANOVA, and ANCOVA analyses. Review of Educational Research. 1998 Sep $1 ; 68(3): 350-86$

27. Hubble S, Bolton P. Reform of the Disabled Students' Allowance in England. 2016 